\title{
Prevalence and classification of rhinitis in preschool children in Portugal: a nationwide study
}

\author{
M. Morais-Almeida ${ }^{1,2}$, N. Santos ${ }^{1,3}$ A. M. Pereira ${ }^{1,3,4}$, M. Branco-Ferreira ${ }^{2,5}$, C. Nunes ${ }^{2,6}$, \\ J. Bousquet ${ }^{7} \&$ J. A. Fonseca ${ }^{2,3,4,8,9}$ \\ ${ }^{1}$ Immunoallergy Department, Hospital CUF-Descobertas, Lisbon; ${ }^{2}$ Sociedade Portuguesa de Alergologia e Imunologia Clínica (SPAIC), Lisbon; \\ ${ }^{3}$ Allergy and Clinical Immunology Department, Centro Hospitalar S. João EPE, Porto; ${ }^{4}$ Health Information and Decision Sciences \\ Department, Faculdade de Medicina da Universidade do Porto, Porto; ${ }^{5}$ Centro Hospitalar Lisboa Norte, Immunoallergy Department, Lisboa; \\ ${ }^{6}$ Centro de Imunoalergologia do Algarve, Portimão, Portugal; ${ }^{7}$ Department of Allergy and Respiratory Diseases, University Hospital and \\ INSERM, Montpellier, France; ${ }^{8}$ Allergy Unit, Hospital-CUF Porto and Instituto CUF-Diagnóstico e Tratamento Porto; ${ }^{9}$ CINTESIS - Center for \\ Research in Health Technologies and Information Systems, Porto, Portugal
}

To cite this article: Morais-Almeida M, Santos N, Pereira AM, Branco-Ferreira M, Nunes C, Bousquet J, Fonseca JA. Prevalence and classification of rhinitis in preschool children in Portugal: a nationwide study. Allergy 2013; 68: 1278-1288.

\section{Keywords}

classification; epidemiology; preschool children; rhinitis; severity.

\section{Correspondence}

Mário Morais-Almeida, Department of Immunoallergy, Hospital CUF-Descobertas, Rua Mário Botas-Parque das Nações, 1998-018 Lisbon, Portugal.

Tel.: +351-917232267

Fax: $+351-210025220$

E-mail: mmoraisalmeida@netcabo.pt

Accepted for publication 12 June 2013

DOI:10.1111/all.12221

Edited by: Wytske Fokkens

\begin{abstract}
Background: Information on rhinitis epidemiology in preschool children is scarce. Objectives: To estimate, in children with 3-5 years of age, current rhinitis prevalence, to describe rhinitis symptoms and associated sociodemographic characteristics, and to report allergic rhinitis and its impact on asthma (ARIA) classification. Methods: Cross-sectional, nationwide, population-based study including children aged 3-5 years. A multistep selection strategy was used to obtain a representative sample. Data were collected at kindergartens and parish centers by face-to-face interview to caregivers, using an adapted ISAAC questionnaire. 'Current rhinitis' (CR) was defined as the presence of $\geq 1$ rhinitis symptom (repeated sneezing and/ or itchy nose, blocked nose for $>1 \mathrm{~h}$, or runny nose without having a cold/flu) in the last year. Rhinitis lasting $\geq 4$ days/week and $\geq 4$ consecutive weeks was classified as persistent. Moderate-severe disease interfered 'a moderate amount' or 'a lot' in daily activities.

Results: Five thousand and eighteen children were included. CR prevalence was $43.4 \%$ [95\% CI $(42.0-44.8 \%) ; n=2179]$ and that of physician-diagnosed rhinitis was $11.7 \%$ [95\% CI $(10.8-12.6 \%) ; n=588]$. Of children with CR, 67\% reported blocked nose, $48 \%$ rhinorrhea, and $46 \%$ sneezing/itchy nose. Considering ARIA classification, $30 \%$ of the population had mild intermittent, $3 \%$ mild persistent, $7 \%$ moderate-severe intermittent, and 3\% moderate-severe persistent rhinitis. Children with CR had more current wheezing, physician-diagnosed asthma, selfreported food allergy, and family history of allergic disease. These characteristics were also associated with persistent and moderate-severe rhinitis.

Conclusions: This is the first nationwide population-based study reporting rhinitis prevalence and ARIA classification in preschool children. In this age-group, rhinitis is frequent and underdiagnosed. About $25 \%$ children with rhinitis presented moderate-severe disease.
\end{abstract}

\section{Abbreviations}

ARIA, allergic rhinitis and its impact on asthma; ETS, environmental tobacco smoke; ISAAC, International Study of Asthma and Allergies in Childhood; NUTS II, Nomenclature of Territorial Units for Statistics, second level; OECD, Organization for Economic

Co-operation and Development. 
Allergic rhinitis is the most prevalent chronic disease in affluent countries, with a prevalence of up to $40 \%$ in schoolaged children and $30 \%$ in adults (1-4). In preschool children, however, epidemiological data on rhinitis prevalence are scarce (5-7).

Allergic rhinitis and its impact on asthma (ARIA) recently recommended that studies should be performed in preschoolers to better understand the disease prevalence and phenotypes (8). However, in epidemiological studies, the definition of 'rhinitis', especially in young children, is challenging. Previous studies (5) have shown that 'rhinitis' is frequently underdiagnosed in this age-group, which hampers the use of self-reported physician-diagnosed rhinitis as the most appropriate 'rhinitis' definition. In the past 2 decades, the most widely used definitions were based on the questionnaire items from the validated International Study of Asthma and Allergies in Childhood (ISAAC) (9). ISAAC questions were considered appropriate to define 'rhinitis' (10).

The ARIA classification, which ranks rhinitis according to its duration and severity, has been developed for use in allergic rhinitis (4). In adults, the ARIA classification has already been used to classify rhinitis irrespective of the atopy status (11).

To our knowledge, there is no population-based, nationwide study reporting the prevalence of rhinitis or the ARIA classification of rhinitis in preschool children. The aims of this study were to assess (i) the prevalence of rhinitis in preschool children (3-5 years) based on the ISAAC questionnaire (9), (ii) individual rhinitis symptoms, (iii) the ARIA classification, and (iv) sociodemographic characteristics associated with rhinitis in this age-group.

\section{Methods}

\section{Study design}

This study was a cross-sectional, nationwide, descriptive study in Portuguese children between 3 and 5 years of age. A questionnaire was applied by interviewers to characterize rhinitis, its severity and common risk factors or comorbidities.

This study was conducted according to the principles of the Helsinki Declaration. Verbal informed consent was obtained from the caretakers of all participating children. This procedure was approved by the Ethics Committee of the Hospital CUF-Descobertas, Lisbon, Portugal.

\section{Setting}

This study was held in mainland Portugal, which is divided into five regions (second level of the Nomenclature of Territorial Units for Statistics - NUTS II) and 278 municipalities. The 2001 Census of the Portuguese Population (12) reported the existence of 296434 children with 3-5 years of age in mainland Portugal. The Organization for Economic Co-operation and Development (OECD) (13) stated that in 2005, more than $80 \%$ of the Portuguese children with 4 years of age and more than $60 \%$ of those with 3 years attended kindergartens.

\section{Sample size}

Based on published data (3), we expected a prevalence of rhinitis in preschool children of $20 \%$. To classify rhinitis according to ARIA, and considering that only around $10 \%$ of children would have more severe and persistent forms of rhinitis, with a margin of error of $1.9 \%$ and a confidence interval of $95 \%$, we would need to evaluate at least 1000 individuals with current rhinitis. With a margin of error of $1 \%$ and with a confidence interval of $95 \%$, we would need 5000 participants to be able to characterize the prespecified number of children. To account for refusal, 500 additional individuals would need to be contacted.

\section{Participants}

Portuguese children, with 3-5 years of age, were eligible to participate. A multistep selection strategy was used to obtain a representative sample of the target population. First, the number of participants needed from each Portuguese region was defined based on the data from the 2001 Census on 3- to 5-year-old children (12). Second, Portuguese municipalities were randomly selected until reaching a prespecified number of children, considering that each municipality would provide between 50 and 70 individuals (Table S1 and Figure S1). Finally, kindergartens and parish centers within the selected municipalities were chosen for data collection; the choice of these sites was based on children's distribution (13), comfort, privacy, and low interference with the usual activities of the participants. Within each selected kindergarten or parish center, all the caregivers of children with 3-5 years of age were invited to participate. A few additional children were recruited in the selected municipalities outside of schools; this convenience or accidental sample corresponds to $<5 \%$ of the included children.

\section{Data collection}

Data were collected using a structured questionnaire, administered by face-to-face interview to the caregivers. The fieldwork was conducted between February and March 2007 by trained interviewers.

\section{Variables}

The questionnaire used in this study was primarily adapted from the Portuguese version of the ISAAC questionnaire (9) for young children (6-7 years). It included questions on rhinitis symptoms (repeated sneezing and/or itchy nose, blocked and runny nose), severity, impact and treatment, as well as physician-diagnosed rhinitis (PDR); data on current wheezing, physician-diagnosed asthma, personal history of food or drug allergy, family history of allergic disease (parents and siblings), exposure to environmental tobacco smoke (ETS) at home, area of residence (urban $v s$ rural), and birthweight were also collected. Tables S2 and S3 report the study's questionnaire and the questions' sources. 
Table 1 Definitions of the variables included in the study. The study questionnaire and the sources of the questions are presented as supplementary material

\begin{tabular}{ll}
\hline Variable & Definition \\
\hline Current rhinitis & $\begin{array}{l}\text { Presence in the last } 12 \text { months of sneezing and/or itchy nose, or a runny, or blocked nose without } \\
\text { having a cold or flu } \\
\text { Intermittent rhinitis }\end{array}$ \\
$\begin{array}{l}\text { Current rhinitis with nasal symptoms lasting }<4 \text { days in a week or lasting more than } 4 \text { days/week but } \\
\text { Persistent rhinitis }\end{array}$ & Current rhinitis with nasal symptoms lasting for at least 4 days in a week and for more than \\
& 4 consecutive weeks \\
Mild rhinitis & Current rhinitis that is referred by the respondent to interfere 'not at all' or 'a little' in the child's daily \\
& activities, in the past 12 months (self-reported severity) \\
Moderate-severe rhinitis & Current rhinitis that is referred by the respondent to interfere 'a moderate amount' or 'a lot' in \\
& the child's daily activities, in the past 12 months (self-reported severity) \\
Physician-diagnosed rhinitis & Positive answer to the question 'Has a doctor ever said the child has rhinitis?' \\
Rhinoconjunctivitis & Presence of current rhinitis and a positive answer to the question: 'In the past 12 months, has this \\
& nose problem been usually accompanied by itchy-watery eyes?' \\
Current wheezing (CW) & Positive answer to the question 'Has the child had wheezing episodes over the last 12 months?' \\
Self-reported food allergy & Positive answer to the question 'Does the child have allergy to any foodstuff?' \\
Self-reported drug allergy & Positive answer to the question 'Does the child have allergy to any medication?' \\
Exposure to environmental & Exposure, at home, to at least one smoker (defined by a positive answer to the question 'Does \\
tobacco smoke (ETS) & anyone who lives with the child smoke at home?') \\
at home &
\end{tabular}

\section{Definitions}

The definitions used in this study are presented in Table 1.

Current rhinitis was classified, according to the ARIA guidelines (4), in intermittent/persistent and mild/moderatesevere rhinitis. This classification has been used in a birth cohort at 13 years of age (14).

\section{Bias}

To avoid bias related to inadequate data collection, interviewers had specific training in the study's subject and in data collection by face-to-face interview. The questionnaire was kept simple and brief, which facilitated the inclusion of participants and minimized the loss of 'compliance' throughout the interview. The strict anonymity maintained throughout study might have contributed to increased reliability of the answers.

\section{Statistical analysis}

Categorical variables were described using absolute frequencies and proportions with $95 \%$ confidence intervals $(95 \%$ CI); comparisons were performed with Pearson's and linearby-linear association qui-square tests. Continuous variables were described using mean with standard deviation (SD); comparisons were performed with independent-samples $t$-test. When necessary, continuous variables were categorized to perform statistical analysis (e.g., birthweight). A $P$-value of $<0.05$ was considered statistically significant.

Additionally, univariate and multiple logistic regression analyses were performed; a description of these statistical methods and the results obtained are available as supplementary material ('Methods: Regression analysis' and Table S6).
All the data analyses were performed using SPSs ${ }^{\circledR}$ version 19.0 for Windows (IBM SPSS, Chicago, IL, USA).

\section{Results}

\section{Participants}

Overall, 5500 individuals were contacted and 5030 participated. Those without complete information regarding 'current rhinitis' $(n=12)$ were excluded from the analysis (Fig. 1). 90 children could not be classified according to ARIA; information regarding missing data is available in Fig. 1. The characteristics of 5018 included children are presented in Table 2.

\section{Main results}

'Current rhinitis' and 'rhinoconjunctivitis' using the ISAAC definition

The prevalence of 'current rhinitis' using the ISAAC definition was $43.4 \%$ [95\% CI $(42.0-44.8 \%) ; n=2179]$ (Table 3). Of children with 'current rhinitis', 66.7\% $(n=1453)$ reported to have blocked nose, $47.7 \%(n=1039)$ to have rhinorrhea, and $45.8 \%(n=997)$ sneezing/itchy nose; $13.2 \% \quad(n=287)$ had all symptoms listed in the questionnaire. Symptoms of conjunctivitis were reported by $759(35.6 \%)$ of children with 'current rhinitis', accounting for a prevalence of rhinoconjunctivitis of $15.3 \%$ [95\% CI (14.3-16.3\%)] (Table 3).

\section{'Current rhinitis' severity and ARIA classification}

In $66.5 \%$ of children with 'current rhinitis', symptoms affected day-to-day routine over the last 12 months: 'a little' in $42.1 \%$, 'a moderate amount' in $19.1 \%$, and 'a lot' in $5.3 \%$. Children with persistent rhinitis reported more interference 


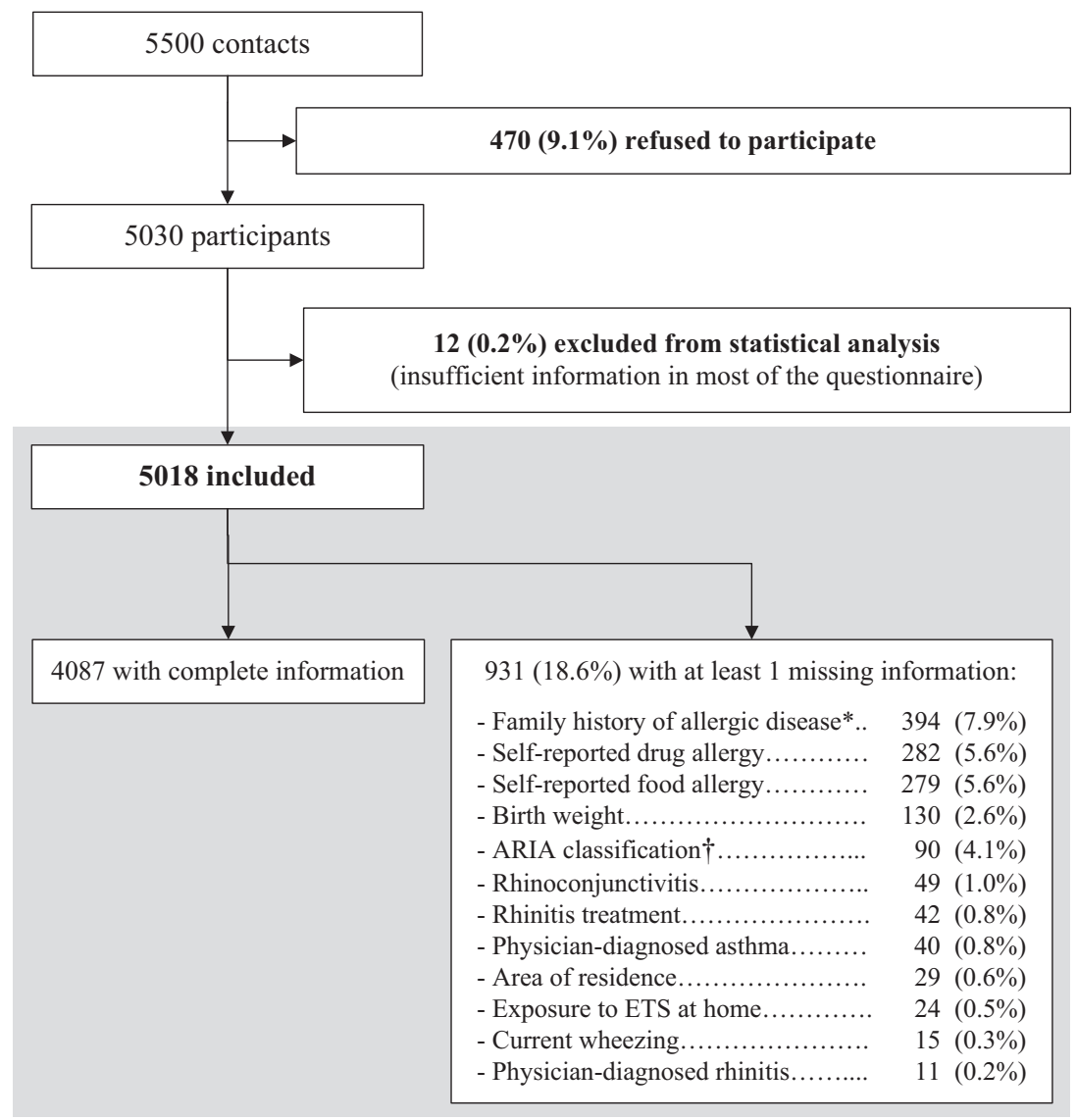

*, $302(6.0 \%)$ with missing information on the father, $202(4.0 \%)$ on the mother and $107(2.1 \%)$ on the siblings (1729 participants had no siblings); $\dagger$, the presented percent considers children with "current rhinitis"

Figure 1 Patient selection diagram and missing data regarding the study's variables.

with daily routine than those with intermittent symptoms (20.1 vs $2.9 \%$ with 'a lot' of interference, respectively, $P<0.001)$. Considering the ARIA classification, $29.5 \%$ [95\% CI (28.5-30.8)] of the children had mild intermittent rhinitis, $2.6 \%$ [95\% CI (2.2-3.0)] mild persistent, $7.2 \%$ [95\% CI (6.5-7.9)] moderate-severe intermittent, and 3.2\% [95\% CI (2.7-3.7)] moderate-severe persistent disease (Table 4).

\section{'Current rhinitis' risk factors and comorbidities}

Children living in a rural area had a significantly lower prevalence of 'current rhinitis'. Children with 'current rhinitis' had more 'current wheezing', 'physician-diagnosed asthma', 'self-reported food allergy', and 'family history of allergic disease' than those without rhinitis. Similar results were found in children with rhinoconjunctivitis (Table S4). In univariate analysis, current wheezing presented the strongest association with 'current rhinitis' $\{\mathrm{OR}=3.95[95 \% \mathrm{CI}(3.44-4.54)]\}$ and one of the strongest with rhinoconjunctivitis $\{\mathrm{OR}=3.50$ [95\% CI (2.98-4.11)]; Table S6\}. In the multivariate analysis including possible risk factors, family history of allergic disease and living in an urban area were positively associated with both 'current rhinitis' and 'rhinoconjunctivitis' (Table S6).
Children with 'current wheezing' and those with family history of allergic disease, when compared to those without, presented higher prevalence of all ARIA classes of rhinitis; those with 'physician-diagnosed asthma', 'self-reported food allergy', and 'self-reported drug allergy' had higher prevalence of more persistent and severe forms of the disease (Table 4). Children living in an urban area had a higher prevalence of intermittent rhinitis (39.0 vs $29.4 \%$ in those living in rural areas, $P<0.001$ ), and children with ETS exposure at home had a lower prevalence of moderate-severe rhinitis (8.1 vs $11.4 \%$ in those without ETS exposure, $P<0.001$; Table 4). A comparison between children without rhinitis and those with different ARIA classes of rhinitis is readily available in Table $\mathrm{S} 5$.

'Physician-diagnosed rhinitis': prevalence and risk factors Physician-diagnosed rhinitis (PDR) was found in $11.7 \%$ [95\% CI $(10.8-12.6 \%) ; n=588]$ children. It was more frequent in children with 'current rhinitis' (26.4 vs $0.5 \%$ in those without rhinitis, $P<0.001)$, especially when associated with nasal and ocular symptoms (44.4 vs $5.6 \%$ in those without 'rhinoconjunctivitis', $P<0.001$; Table 3 ) and in moderatesevere disease $(51.0$ vs $46.4 \%$ in mild rhinitis, $P<0.001$; 
Table 2 Characteristics of the participants $(n=5018)$

\begin{tabular}{lc}
\hline & $N\left(\%{ }^{*}\right)$ \\
\hline Male gender & $2561(51.0)$ \\
Age (years) & \\
3 & $1678(33.4)$ \\
4 & $1669(33.3)$ \\
5 & $1671(33.3)$ \\
Birthweight (kg) & \\
$<2.50$ & $633(13.0)$ \\
$\geq 2.50$ until 3.99 & $3923(80.3)$ \\
$\geq 4.00$ & $330(6.8)$ \\
Living in a urban area & $3792(76.0)$ \\
Current wheezing & $1228(24.5)$ \\
Physician-diagnosed asthma, ever & $228(4.6)$ \\
Self-reported food allergy & $316(6.7)$ \\
Self-reported drug allergy & $129(2.7)$ \\
Family history of allergic disease, present & $1419(30.7)$ \\
Father & $567(12.0)$ \\
Mother & $830(17.2)$ \\
Sibling & $326(10.2)$ \\
Exposed to ETS at home & $1528(30.6)$ \\
\hline
\end{tabular}

ETS, environmental tobacco smoke exposure.

*Valid percents.

Table 4). Risk factors and risk markers for PDR were similar to those found for 'current rhinitis' and 'rhinoconjunctivitis' (Tables 3 and Table S6).

\section{Rhinitis underdiagnosis}

Seventy-four percent $(n=1601)$ of children with 'current rhinitis' had no previous PDR (Table 5). Children with underdiagnosed disease presented milder rhinitis $(85.4 \%$ of children without PDR had mild disease vs $47.6 \%$ of those previously diagnosed, $P<0.001)$ and more intermittent symptoms (89.9 vs $77.3 \%$, respectively, $P<0.001$ ). Children with 'current rhinitis' without PDR had less 'current wheezing', 'physician-diagnosed asthma', self-reported food and drug allergy, and less maternal and sibling's history of allergic disease (Table 5).

\section{Rhinitis treatment}

Twenty-six percent $(n=563)$ of the children with 'current rhinitis' received rhinitis treatment (topical or oral) in the previous year. It was more frequently used in children with moderate-severe rhinitis (56.4 vs $16.3 \%$ in mild rhinitis, $P<0.001)$, in those with PDR $(92.8 v s 0.9 \%$ in those without, $P<0.001$ ), and those with 'rhinoconjunctivitis' (44.5 vs $5.5 \%$ in those without current nasal and ocular symptoms, $P<0.001$ ) (Tables S4 and S5).

\section{Discussion}

\section{Key results}

Over $40 \%$ of Portuguese preschool children had 'current rhinitis' as defined by ISAAC. Only $11.7 \%$ had physician-diagnosed rhinitis (PDR). As defined by ARIA, two-thirds of the children with 'current rhinitis' had mild intermittent disease, $17 \%$ moderate-severe intermittent, over $7 \%$ moderate-severe persistent, and around $6 \%$ mild persistent rhinitis. Children with 'current rhinitis', PDR, and/or rhinoconjunctivitis, when compared to those without, had more 'current wheezing', 'physician-diagnosed asthma', 'self-reported food allergy', and 'family history of allergic disease'. These characteristics were also associated with rhinitis persistency and higher severity.

\section{Strengths and limitations}

This is the first truly nationwide study assessing rhinitis prevalence in preschool children, although population-based studies have been carried out in Sweden (15), Italy (6), and Colombia (7) and some data exist from birth cohorts $(5,16)$. Moreover, this is the first population-based nationwide study in this age-group reporting rhinitis classification according to ARIA.

The major limitations of this study are the lack of physician diagnosis confirmation and allergy assessment. Moreover, this study lacks information on the frequency of rhinitis episodes over the past year; however, by focusing on 'current rhinitis' and on the presence of rhinitis symptoms regardless of their frequency, the possibility of recall bias due to retrospective data collection was minimized.

We used a rhinitis definition similar to ISAAC. However, in our study, the presence of blocked nose, sneezing, and rhinorrhea was independently asked, while in ISAAC, a single question globally assessed the same symptoms (9); it is unknown whether the use of these two different ways to perform the same question may have elicited divergent responses. Moreover, questionnaire-based definition of rhinitis, without clinical correlation, may lead to misclassification of the studies' participants (17). Furthermore, the ISAAC rhinitis-specific questions were originally validated in children by comparison with aeroallergen sensitization (18), which is arguable. To our knowledge, only a recent study reported a validation of ISAAC questions (regarding rhinitis symptoms and rhinoconjunctivitis) against physician-diagnosed allergic rhinitis (17), and they were associated with only moderate accuracy. Considering ARIA (4), which recommends the use of atopy objective markers to define allergic rhinitis (AR), and the limitations of the ISAAC questions in defining AR, in our study, only 'rhinitis', without specification as allergic or nonallergic, was reported. As the cause of rhinitis in preschool children is still poorly understood, it seems appropriate to include an in vivo or in vitro IgE-sensitization marker in future studies.

\section{Interpretation and generalizability}

Rhinitis prevalence was higher than those found for preschool children in cities of Italy $(16.8 \%)$ (6), Sweden $[5.7 \%$ in Varmland (15), 10.8\% in Stockholm (16)], the United Kingdom (26.1\%) (5), and Colombia (30.4\%) (7). This variability may be related to regional differences, age-groups studied [children younger than 3 years of age were included 
Table 3 Prevalence of current rhinitis $(n=5018)$, physician-diagnosed rhinitis $(n=5007)$, and rhinoconjunctivitis $(n=4969)$ according to demographic characteristics and disease status

\begin{tabular}{|c|c|c|c|c|c|c|c|c|c|}
\hline & \multicolumn{3}{|c|}{ 'Current rhinitis' } & \multicolumn{3}{|c|}{ 'Physician-diagnosed rhinitis' } & \multicolumn{3}{|c|}{ 'Rhinoconjunctivitis' } \\
\hline & $n$ & $(\%)$ & {$[95 \% \mathrm{Cl}]$} & $n$ & $(\%)$ & {$[95 \% \mathrm{Cl}]$} & $n$ & $(\%)$ & {$[95 \% \mathrm{Cl}]$} \\
\hline All & 2179 & $(43.4)$ & {$[42.0-44.8]$} & 588 & $(11.7)$ & {$[10.8-12.6]$} & 759 & (15.3) & [14.3-16.3] \\
\hline Gender & $0.281^{*}$ & & & $0.304^{*}$ & & & $0.035^{*}$ & & \\
\hline Male & 1131 & $(44.2)$ & [42.3-46.1] & 312 & (12.2) & [10.9-13.5] & 414 & (16.3) & [14.9-17.7] \\
\hline Female & 1048 & $(42.7)$ & {$[40.7-44.7]$} & 276 & (11.3) & [10.0-12.6] & 345 & $(14.2)$ & [12.8-15.6] \\
\hline Age (years) & $0.361^{*}$ & & & $0.998 *$ & & & $0.557^{*}$ & & \\
\hline 3 & 740 & $(44.1)$ & {$[41.7-46.5]$} & 196 & $(11.7)$ & [10.2-13.2] & 258 & (15.5) & [13.8-17.2] \\
\hline 4 & 737 & $(44.2)$ & [41.8-46.6] & 196 & (11.8) & [10.3-13.3] & 261 & (15.8) & [14.0-17.6] \\
\hline 5 & 702 & $(42.0)$ & [39.6-44.4] & 196 & (11.8) & [10.3-13.3] & 240 & (14.5) & [12.8-16.2] \\
\hline Birthweight (kg) & $0.002^{*}$ & & & $0.001 *$ & & & $0.062^{*}$ & & \\
\hline$<2.50$ & 307 & (48.5) & {$[44.6-52.4]$} & 98 & (15.6) & {$[12.8-18.4]$} & 105 & (16.9) & [14.0-19.8] \\
\hline$\geq 2.50$ until 3.99 & 1705 & (43.5) & {$[41.9-45.1]$} & 429 & (10.9) & [9.9-11.9] & 604 & (15.5) & [14.4-16.6] \\
\hline$\geq 4.00$ & 121 & $(36.7)$ & [31.5-41.9] & 47 & $(14.2)$ & [10.4-18.0] & 36 & (11.1) & {$[7.7-14.5]$} \\
\hline Area of residence & $<0.001^{*}$ & & & $<0.001^{*}$ & & & $0.002^{*}$ & & \\
\hline Urban & 1739 & (45.9) & [44.3-47.5] & 486 & (12.8) & [11.7-13.9] & 606 & (16.1) & [14.9-17.3] \\
\hline Rural & 427 & $(35.7)$ & [33.0-38.4] & 101 & (8.4) & {$[6.8-10.0]$} & 147 & (12.5) & [10.6-14.4] \\
\hline Current rhinitis & NA & & & $<0.001^{*}$ & & & & & \\
\hline Without current rhinitis & & & & 15 & (0.5) & {$[0.2-0.8]$} & NA & & \\
\hline With current rhinitis & & & & 573 & (26.4) & [24.5-28.3] & 759 & (35.6) & [33.6-37.6] \\
\hline Physician-diagnosed rhinitis (PDR) & $<0.001^{*}$ & & & NA & & & $<0.001^{*}$ & & \\
\hline Without PDR & 1601 & $(36.2)$ & [34.8-37.6] & & & & 421 & $(9.6)$ & {$[8.7-10.5]$} \\
\hline With PDR & 573 & $(97.4)$ & [96.1-98.7] & & & & 336 & $(58.8)$ & [54.8-62.8] \\
\hline Rhinoconjunctivitis & NA & & & $<0.001^{*}$ & & & NA & & \\
\hline Without rhinoconjunctivitis & & & & 235 & $(5.6)$ & [4.9-6.3] & & & \\
\hline With rhinoconjunctivitis & & & & 336 & $(44.4)$ & {$[40.9-47.9]$} & & & \\
\hline Rhinitis treatment & $<0.001^{*}$ & & & $<0.001^{*}$ & & & $<0.001^{*}$ & & \\
\hline Without rhinitis treatment & 1592 & $(36.2)$ & [34.8-37.6] & 42 & (1.0) & {$[0.7-1.3]$} & 417 & (9.6) & [8.7-10.5] \\
\hline With rhinitis treatment & 563 & $(96.7)$ & [95.2-98.2] & 544 & (93.5) & [91.5-95.5] & 335 & $(59.2)$ & [55.2-63.2] \\
\hline Current wheezing & $<0.001^{*}$ & & & $<0.001^{*}$ & & & $<0.001^{*}$ & & \\
\hline Without current wheezing & 1336 & (35.4) & [33.9-36.9] & 323 & (8.6) & {$[7.7-9.5]$} & 401 & (10.7) & {$[9.7-11.7]$} \\
\hline With current wheezing & 840 & (68.4) & {$[65.8-71.0]$} & 265 & $(21.7)$ & {$[19.4-24.0]$} & 358 & (29.6) & [27.0-32.2] \\
\hline $\begin{array}{l}\text { Physician-diagnosed asthma } \\
\text { (PDA), ever }\end{array}$ & $<0.001^{*}$ & & & $<0.001^{*}$ & & & $<0.001^{*}$ & & \\
\hline Without PDA & 1997 & $(42.0)$ & {$[40.6-43.4]$} & 510 & $(10.8)$ & & 652 & (13.9) & [12.9-14.8] \\
\hline With PDA & 167 & $(73.2)$ & [67.5-78.9] & 76 & (33.5) & [27.4-39.6] & 100 & $(44.8)$ & [38.3-51.3] \\
\hline Self-reported food allergy & $0.003^{*}$ & & & $0.001^{*}$ & & & $<0.001^{*}$ & & \\
\hline Without food allergy & 1946 & $(44.0)$ & {$[42.5-45.5]$} & 522 & (11.8) & {$[10.8-12.8]$} & 663 & $(15.1)$ & [14.0-16.2] \\
\hline With food allergy & 166 & (52.5) & {$[47.0-58.0]$} & 58 & (18.4) & {$[14.1-22.7]$} & 84 & (26.8) & [21.9-31.7] \\
\hline Self-reported drug allergy & $0.650^{*}$ & & & $0.077^{*}$ & & & $0.001^{*}$ & & \\
\hline Without drug allergy & 2050 & $(44.5)$ & [43.1-45.9] & 557 & $(12.1)$ & {$[11.1-13.0]$} & 712 & $(15.6)$ & [14.5-16.7] \\
\hline With drug allergy & 60 & $(46.5)$ & [37.9-55.1] & 22 & (17.3) & [10.8-23.8] & 34 & (26.6) & [18.9-34.3] \\
\hline Family history of allergic disease & $<0.001^{*}$ & & & $<0.001^{*}$ & & & $<0.001^{*}$ & & \\
\hline Without family history & 1267 & (39.5) & [37.8-41.2] & 296 & (9.3) & [8.3-10.3] & 370 & $(11.7)$ & [10.6-12.8] \\
\hline With family history & 752 & $(53.0)$ & {$[50.4-55.6]$} & 250 & $(17.7)$ & [15.7-19.7] & 315 & $(22.4)$ & [20.2-24.6] \\
\hline Father & 308 & (54.3) & {$[50.2-58.4]$} & 92 & (16.3) & [13.3-19.3] & 138 & $(24.4)$ & [20.9-27.9] \\
\hline Mother & 451 & (54.3) & {$[50.9-57.7]$} & 161 & (19.4) & {$[16.7-22.1]$} & 186 & $(22.7)$ & [19.8-25.6] \\
\hline Sibling & 159 & (48.8) & [43.4-54.2] & 63 & (19.3) & {$[15.0-23.6]$} & 72 & (22.3) & [17.8-26.8] \\
\hline Exposure to ETS at home & $0.831^{*}$ & & & $0.341^{*}$ & & & $0.370^{*}$ & & \\
\hline Not exposed to ETS & 1504 & $(43.4)$ & {$[41.8-45.0]$} & 418 & $(12.1)$ & {$[11.0-13.2]$} & 537 & (15.6) & [14.4-16.8] \\
\hline Exposed to ETS & 668 & $(43.7)$ & {$[41.2-46.2]$} & 170 & (11.1) & {$[9.5-12.7]$} & 221 & (14.6) & [12.8-16.4] \\
\hline
\end{tabular}

ETS, environmental tobacco smoke.

* P-value for difference between prevalence (considering different categories of each characteristic/disease status). 


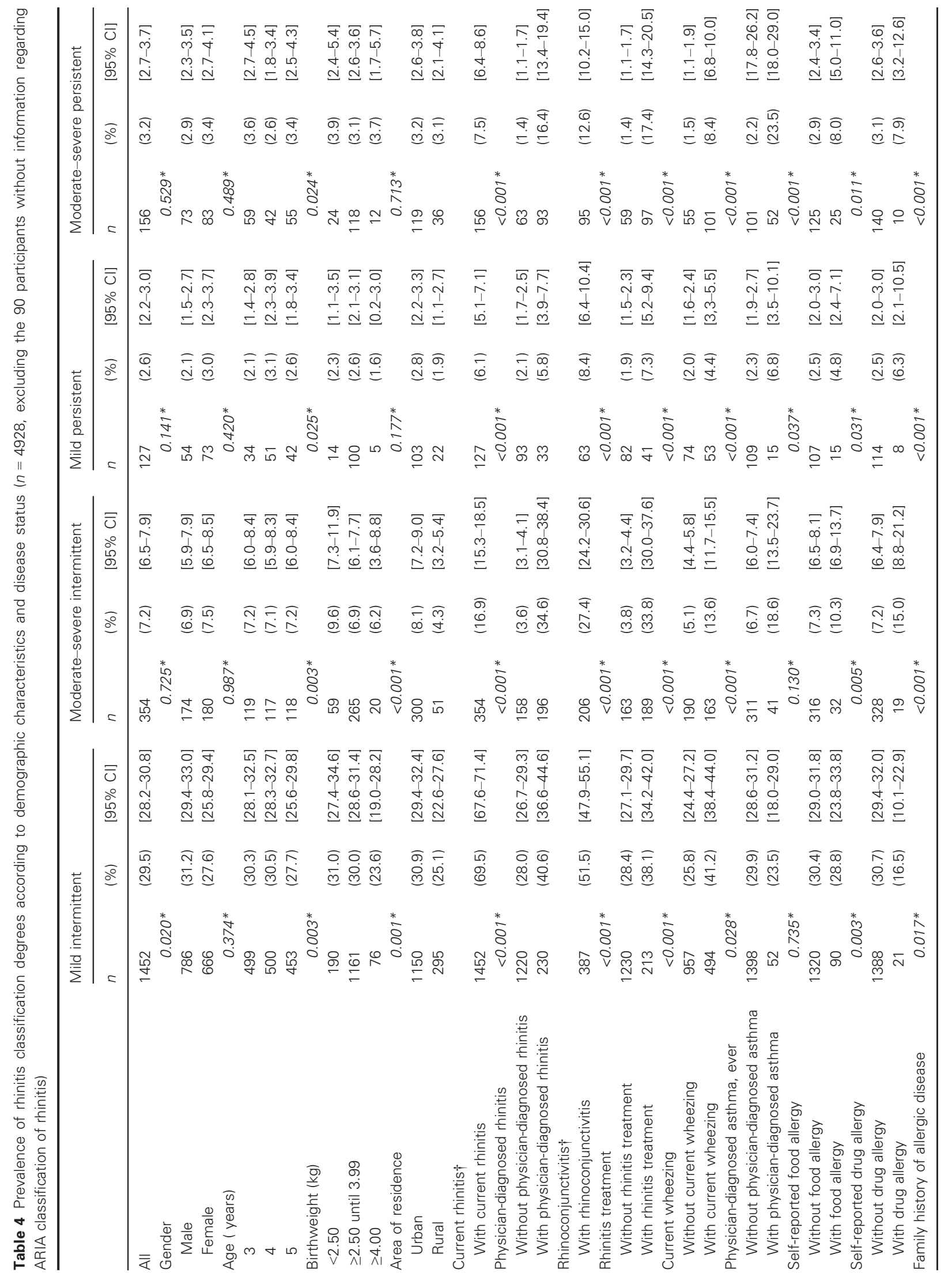




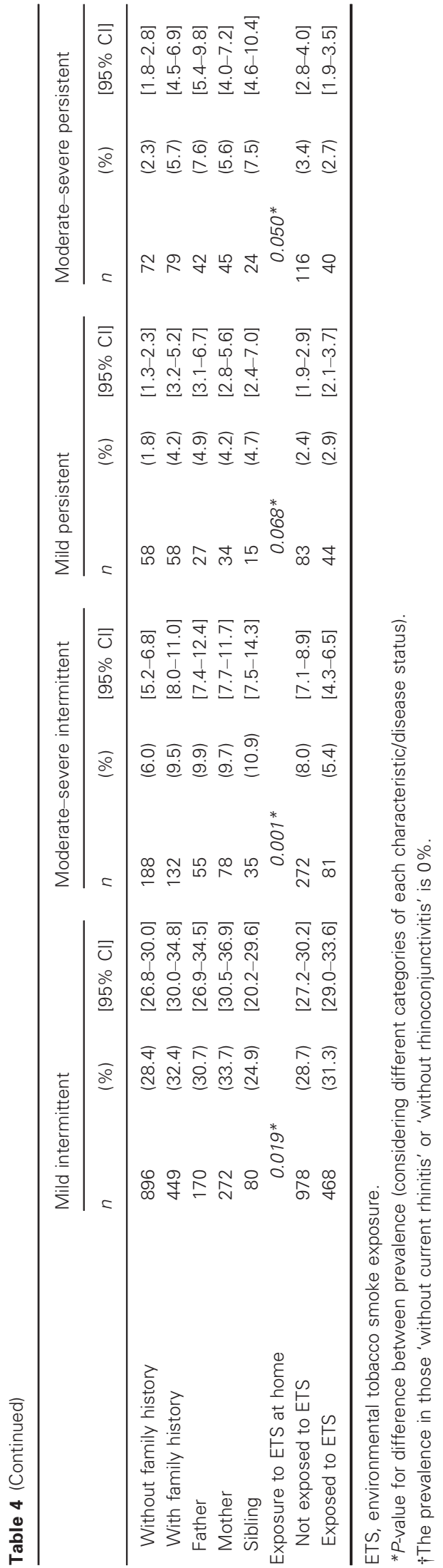

Table 5 Characteristics of children with 'current rhinitis' according to the presence or absence of a rhinitis medical diagnosis

\begin{tabular}{|c|c|c|c|}
\hline & \multicolumn{3}{|c|}{$\begin{array}{l}\text { Children with current rhinitis_-ISAAC } \\
(n=2179)\end{array}$} \\
\hline & $\begin{array}{l}\text { With } \\
\text { physician- } \\
\text { diagnosed } \\
\text { rhinitis } \\
{[n=573} \\
(26.4 \%)]\end{array}$ & $\begin{array}{l}\text { Without } \\
\text { physician- } \\
\text { diagnosed } \\
\text { rhinitis } \\
{[n=1601} \\
(73.6 \%)]\end{array}$ & \\
\hline & $n(\%)$ & $n(\%)$ & $P$-value \\
\hline Gender, male & $306(53.4)$ & 822 (51.3) & 0.397 \\
\hline Age (years) & & & 0.792 \\
\hline 3 & 192 (33.5) & $546(34.1)$ & \\
\hline 4 & $190(33.2)$ & $546(34.1)$ & \\
\hline 5 & 191 (33.3) & 509 (31.8) & \\
\hline Birthweight (kg) & & & 0.001 \\
\hline$<2.50$ & 98 (17.5) & 207 (13.2) & \\
\hline$\geq 2.50$ until 3.99 & $419(74.7)$ & $1283(81.9)$ & \\
\hline$\geq 4.00$ & $44(7.8)$ & 77 (4.9) & \\
\hline $\begin{array}{l}\text { Living in an urban } \\
\text { area }\end{array}$ & 477 (83.4) & $1257(79.1)$ & 0.027 \\
\hline Rhinoconjunctivitis & $336(60.4)$ & 421 (26.8) & $<0.001$ \\
\hline Rhinitis treatment & 531 (93.0) & $32(2.0)$ & $<0.001$ \\
\hline Current wheezing & $263(45.9)$ & 574 (35.9) & $<0.001$ \\
\hline $\begin{array}{l}\text { Physician-diagnosed } \\
\text { asthma, ever }\end{array}$ & 76 (13.3) & $91(5.7)$ & $<0.001$ \\
\hline $\begin{array}{l}\text { Self-reported food } \\
\text { allergy }\end{array}$ & $58(10.2)$ & $108(7.0)$ & 0.014 \\
\hline $\begin{array}{l}\text { Self-reported drug } \\
\text { allergy }\end{array}$ & $22(3.9)$ & $37(2.4)$ & 0.065 \\
\hline $\begin{array}{l}\text { Family history of } \\
\text { allergic disease }\end{array}$ & 242 (45.6) & 508 (34.3) & $<0.001$ \\
\hline Father & 87 (16.3) & $220(14.5)$ & 0.321 \\
\hline Mother & $156(28.1)$ & $294(19.0)$ & $<0.001$ \\
\hline Sibling & 60 (16.9) & $99(10.0)$ & 0.001 \\
\hline $\begin{array}{l}\text { Exposed to ETS } \\
\text { at home }\end{array}$ & $163(28.4)$ & $504(31.6)$ & 0.158 \\
\hline
\end{tabular}

ETS, environmental tobacco smoke exposure.

in Varmland - Sweden (15) and Colombia (7)], selection methodology [the Manchester study (5) and the BAMSE study (16) were retrieved from birth cohorts, the Dampness in Building and Health Study (15) was based on a population cohort, while the others were cross-sectional populationbased studies], and definition used. This prevalence is also higher than those of current rhinitis in children aged 6 to 7 years $(23.4 \%$ in Portugal and $21.4 \%$ worldwide) and $13-14$ years $(26.5 \%$ in Portugal and $31.7 \%$ worldwide) reported in ISAAC (19).

We found that the most common nasal symptom was blocked nose, which differs from studies in allergic rhinitis in adults (20). This may be due to the inclusion of children with both allergic and nonallergic rhinitis or to other differential diagnosis that are highly prevalent in preschool children (e.g., adenoidal hypertrophy). These findings suggest that 
ISAAC definition is particularly unspecific in this age-group and that it could be improved. However, the use of an alternative definition (e.g., combination of symptoms) would limit comparability with other reports and would need validation as an epidemiological tool for assessing rhinitis in children.

Few studies have used the ARIA classification in preschoolers, and none included children irrespective of their atopy status. Hamouda et al. (21), when classifying allergic rhinitis in preschool children with current asthma, found a higher prevalence of mild persistent rhinitis $(25 \%)$ and less moderate-severe disease (2\%). Keil et al. (14) presented data from a birth cohort of children with high risk of allergy; they found that $41 \%$ of children with allergic rhinitis defined by ISAAC criteria presented mild persistent and $27 \%$ moderatesevere persistent rhinitis. We also found that as reported for adults (20) and school-aged children (22), persistent forms of rhinitis were associated with increased perceived severity. To our knowledge, the ARIA classification is not validated for use in preschoolers; however, both the original classification (23) and a modified version (22), which considers moderate rhinitis separately from severe rhinitis, were recently validated for use in school-aged children. Moreover, it was never used to classify nonallergic rhinitis in children, although in adults, it was regarded as a useful pragmatic approach (11). In fact, nonallergic rhinitis is frequent in the general population and has no widely accepted classification system (11); the use of a single classification would allow a better comparability between clinical characteristics of allergic and nonallergic rhinitis and would provide a useful tool when atopy status is unknown, as in our study. However, this approach in children still needs validation.

In this study, rhinoconjunctivitis had a similar prevalence to that found by Marinho et al. (5) in preschool children and to the overall global prevalence $(15 \%)$ reported by ISAAC in 13- to 14 year-old children (19). The presence of rhinoconjunctivitis ( $v s$ rhinitis alone) has been regarded as a more probable allergic condition and has been suggested as a useful surrogate marker for 'allergic rhinitis' in epidemiological studies (24). In our report, around one-third of children with current rhinitis presented rhinoconjunctivitis, suggesting that atopy explains only part of current rhinitis symptoms in preschoolers.

Of children with current rhinitis, PDR was referred in $26.4 \%$ and rhinitis treatment was used in $26.1 \%$. Underdiagnosis and lack of treatment could be related to the undervaluation of rhinitis symptoms by both caregivers and physicians, despite the known impact in the child's quality of life (25).

In our study, preschool children with current wheezing, physician-diagnosed asthma, self-reported food allergy, and family history of allergic disease presented significantly higher prevalence of current rhinitis, as previously found $(1,5,6$, $16,26)$. We also report an association between these characteristics and rhinitis severity, which supports that there is a strong link between allergic disorders even at preschool age.

When examining environmental factors, we found that children living in a rural area had lower current rhinitis prevalence. This is not a consensual finding, and both studies reporting similar (27) and opposite (28) results have been published. The exposure to higher levels of outdoor pollutants in urban areas, which were associated with increased nasal symptoms and allergic rhinitis $(29,30)$, may partially explain our findings.

Most studies do not show a clear association between ETS exposure and rhinitis $(31,32)$, although some suggest that ETS is associated with more persistent nasal symptoms (33). In this study, no association was found between ETS exposure at home and current rhinitis, but an inverse association was found with moderate-severe persistent rhinitis. We hypothesize that this finding may be due to a reverse causality phenomenon or a reporting bias in which caregivers of children with more severe and persistent nasal symptoms are more prone to cease smoking or to under-report smoking habits, respectively.

\section{Conclusions}

This was the first population-based nationwide study reporting rhinitis classification according to ARIA in preschool children. More than $40 \%$ of Portuguese preschoolers had current rhinitis, of which about $25 \%$ had moderate-severe disease. Current wheezing, physician-diagnosed asthma, selfreported food allergy, and family history of allergic disease were associated with current rhinitis, namely with persistent and moderate-severe forms.

\section{Acknowledgments}

Methodological support and fieldwork were supplied by KeyPoint, Scientific Consultants. This work was supported by an unrestricted educational independent grant attributed by Schering-Plough Pharma to the Portuguese Society of Allergy and Clinical Immunology (SPAIC).

\section{Author contributions}

AMP and NS participated in data analysis and interpretation and wrote the manuscript draft, $\mathrm{MBF}$ and $\mathrm{CN}$ participated in the study conception, JB provided critical review during the project, JAF participated in data analysis and interpretation and provided critical review during the project, and MMA coordinated the study participating in all stages and tasks. All authors have reviewed and approved the final manuscript.

\section{Conflicts of interest}

Mário Morais-Almeida (MMA) received travel grants, speaking fees, and honoraria for advisory boards from Astrazeneca, GSK, FAES Farma, MSD, Novartis, OM Pharma, Pfizer, Sanofi, Schering-Plough, and Siemens Diagnostics. Manuel Branco-Ferreira (MBF) received honoraria for scientific and advisory boards and lectures during meetings from Almirall, Bial, GSK, MSD, OM Pharma, Shire, and Stallèrgenes. Jean Bousquet (JB) received honoraria for scientific and advisory boards, lectures during meetings, and press conferences from Stallergènes, Actelion, Almirall, AstraZeneca, 
Chiesi, GSK, Merck, MSD, Novartis, OM Pharma, SanofiAventis, Schering Plough, Teva, and Uriach. João Almeida Fonseca (JAF) has received an unrestricted research grant from Aerocrine $\mathrm{AB}$ and honoraria for travel grants and speaking fees and advisory boards from Astrazeneca, GSK, MSD, and Novartis. Ana Margarida Pereira (AMP), Natacha Santos (NS), and Carlos Nunes (CN) have no conflict of interests to declare.

\section{Supporting Information}

Additional Supporting Information may be found in the online version of this article:

Methods. Regression analysis.

Figure S1. Distribution of the included children across mainland Portugal.
Table S1. Comparison between the Portuguese population aged 3-5 years, the predicted sample and the true sample, considering region and age.

Table S2. Study questionnaire.

Table S3. Sources of the included questions.

Table S4. Comparison between children with and without 'current rhinitis', 'physician-diagnosed rhinitis' and 'rhinoconjunctivitis'.

Table S5. Comparison between children without rhinitis and those with different forms of current rhinitis, considering the ARIA classification.

Table S6. Univariate (unadjusted) and multivariate (adjusted) analysis for risk of 'current rhinitis', 'physiciandiagnosed rhinitis' or 'rhinoconjunctivitis' (multivariate analysis included only possible risk factors). Statistically significant results are presented in bold.

\section{References}

1. Wright AL, Holberg CJ, Martinez FD, Halonen M, Morgan W, Taussig LM. Epidemiology of physician-diagnosed allergic rhinitis in childhood. Pediatrics 1994;94(6 Pt 1):895-901.

2. Bauchau V, Durham SR. Prevalence and rate of diagnosis of allergic rhinitis in Europe. Eur Respir J 2004;24:758-764.

3. Strachan D, Sibbald B, Weiland S, Ait-Khaled N, Anabwani G, Anderson HR et al. Worldwide variations in prevalence of symptoms of allergic rhinoconjunctivitis in children: the International Study of Asthma and Allergies in Childhood (ISAAC). Pediatr Allergy Immunol 1997;8:161-168.

4. Bousquet J, Khaltaev N, Cruz AA, Denburg J, Fokkens WJ, Togias A et al. Allergic Rhinitis and its Impact on Asthma (ARIA) 2008. Allergy 2008;63:8-160.

5. Marinho S, Simpson A, Lowe L, Kissen P, Murray C, Custovic A. Rhinoconjunctivitis in 5-year-old children: a population-based birth cohort study. Allergy 2007;62:385-393.

6. Peroni DG, Piacentini GL, Alfonsi L, Zerman L, Di Blasi P, Visona G et al. Rhinitis in pre-school children: prevalence, association with allergic diseases and risk factors. Clin Exp Allergy 2003;33:13491354.

7. Dennis RJ, Caraballo L, Garcia E, Rojas MX, Rondon MA, Perez A et al. Prevalence of asthma and other allergic conditions in Colombia 2009-2010: a cross-sectional study. BMC Pulm Med 2012;12:17.

8. Bousquet J, Schunemann HJ, Samolinski B, Demoly P, Baena-Cagnani CE, Bachert C et al. Allergic Rhinitis and its Impact on Asthma (ARIA): achievements in 10 years and future needs. J Allergy Clin Immunol 2012;130:1049-1062.

9. Asher MI, Keil U, Anderson HR, Beasley R, Crane J, Martinez F et al. International Study of Asthma and Allergies in Childhood
(ISAAC): rationale and methods. Eur Respir $J$ 1995;8:483-491.

10. Pinart M, Maier D, Gimeno-santos E, Sola I, Garcia-aymerich J, Guerra S et al. Systematic review protocol to define classical IgE-associated diseases from birth to adolescence: the MeDALL study. WebmedCentral ALLERG Y 2012;3:WMC003408.

11. Bachert C, van Cauwenberge P, Olbrecht J, van Schoor J. Prevalence, classification and perception of allergic and nonallergic rhinitis in Belgium. Allergy 2006;61:693-698.

12. Instituto Nacional de Estatística. Censos 2001: Resultados definitivos. XIV Recenseamento geral da População. Lisbon: INE, 2002.

13. OECD. Education at a Glance 2012: OECD Indicators. In. http://dx.doi.org/10.1787/ eag-2012-en: OECD Publishing; 2012. pp. 338-347.

14. Keil T, Bockelbrink A, Reich A, Hoffmann U, Kamin W, Forster $\mathbf{J}$ et al. The natural history of allergic rhinitis in childhood. Pediatr Allergy Immunol 2010;21:962-969.

15. Larsson M, Hagerhed-Engman L, Sigsgaard T, Janson S, Sundell J, Bornehag CG. Incidence rates of asthma, rhinitis and eczema symptoms and influential factors in young children in Sweden. Acta Paediatr 2008;97:1210-1215.

16. Ballardini N, Kull I, Lind T, Hallner E, Almqvist C, Ostblom E et al. Development and comorbidity of eczema, asthma and rhinitis to age 12: data from the BAMSE birth cohort. Allergy 2012;67:537-544.

17. Kim H, Levin L, LeMasters GK, Villareal M, Evans S, Lockey JE et al. Validating childhood symptoms with physician-diagnosed allergic rhinitis. Ann Allergy Asthma Immunol 2012;108:228-231.

18. Braun-Fahrlander C, Wuthrich B, Gassner M, Grize L, Sennhauser FH, Varonier HS et al. Validation of a rhinitis symptom questionnaire (ISAAC core questions) in a population of Swiss school children visiting the school health services. Pediatr Allergy Immunol 1997;8:75-82.

19. Ait-Khaled N, Pearce N, Anderson HR, Ellwood P, Montefort S, Shah J. Global map of the prevalence of symptoms of rhinoconjunctivitis in children: The International Study of Asthma and Allergies in Childhood (ISAAC) Phase Three. Allergy 2009;64:123-148.

20. Todo-Bom A, Loureiro C, Almeida MM, Nunes C, Delgado L, Castel-Branco G et al. Epidemiology of rhinitis in Portugal: evaluation of the intermittent and the persistent types. Allergy 2007;62:1038-1043.

21. Hamouda S, Karila C, Connault T, Scheinmann P, de Blic J. Allergic rhinitis in children with asthma: a questionnairebased study. Clin Exp Allergy 2008;38: 761-766.

22. Montoro J, Del Cuvillo A, Mullol J, Molina X, Bartra J, Dávila I et al. Validation of the modified allergic rhinitis and its impact on asthma (ARIA) severity classification in allergic rhinitis children: the PEDRIAL study. Allergy 2012;67:1437-1442.

23. Jauregui I, Davila I, Sastre J, Bartra J, del Cuvillo A, Ferrer M et al. Validation of ARIA (Allergic Rhinitis and its Impact on Asthma) classification in a pediatric population: the PEDRIAL study. Pediatr Allergy Immunol 2011;22:388-392.

24. Weinmayr G, Forastiere F, Weiland SK, Rzehak P, Abramidze T, Annesi-Maesano I et al. International variation in prevalence of rhinitis and its relationship with sensitisation to perennial and seasonal allergens. Eur Respir J 2008;32:1250-1261.

25. Maurer M, Zuberbier T. Undertreatment of rhinitis symptoms in Europe: findings from a cross-sectional questionnaire survey. Allergy 2007;62:1057-1063. 
26. Alm B, Goksor E, Thengilsdottir H, Pettersson R, Mollborg P, Norvenius G et al. Early protective and risk factors for allergic rhinitis at age 4(1/2) yr. Pediatr Allergy Immunol 2011;22:398-404.

27. Eriksson J, Ekerljung L, Lotvall J, Pullerits T, Wennergren G, Ronmark E et al. Growing up on a farm leads to lifelong protection against allergic rhinitis. Allergy 2010;65:1397-1403.

28. Brunekreef B, Von Mutius E, Wong GK, Odhiambo JA, Clayton TO. Early life exposure to farm animals and symptoms of asthma, rhinoconjunctivitis and eczema: an
ISAAC Phase Three Study. Int J Epidemiol 2012;41:753-761.

29. Rodriguez C, Tonkin R, Heyworth J, Kusel M, De Klerk N, Sly PD et al. The relationship between outdoor air quality and respiratory symptoms in young children. Int $J$ Environ Health Res 2007;17:351-360.

30. Penard-Morand C, Raherison C, Charpin D, Kopferschmitt C, Lavaud F, Caillaud D et al. Long-term exposure to close-proximity air pollution and asthma and allergies in urban children. Eur Respir J 2010;36:33-40.

31. Vlaski E, Stavric K, Seckova L, Kimovska M, Isjanovska R. Do household tobacco smoking habits influence asthma, rhinitis and eczema among 13-14 year-old adolescents? Allergol Immunopathol (Madr) 2011;39:39-44.

32. Lin SY, Reh DD, Clipp S, Irani L, NavasAcien A. Allergic rhinitis and secondhand tobacco smoke: a population-based study. Am J Rhinol Allergy 2011;25:e66-e71.

33. Virkkula P, Liukkonen K, Suomalainen AK, Aronen ET, Kirjavainen T, Pitkaranta A. Parental smoking, nasal resistance and rhinitis in children. Acta Paediatr 2011;100:12341238 . 